\title{
A Comparative Study of Korean mistletoe lectin and bee venom on mechanism in inducing apoptosis of Hep G2, a liver cancer cell
}

\author{
Seong-Woo Lim \\ Department of Korean Internal Medicine, Ilsan Oriental Hospital of Dongguk University.
}

Objectives: The objective of this study is Korean mistletoe lectin (Viscum album coloratum agglutinin, VCA) and bee venom (BV) to experimental prove comparative study of VCA and BV on the anti-cancer effect and mechanisms of action. Methods: In this study, it was examined in a human hepatocellular carcinoma cell line, Hep G2 cells. Cytotoxic effects of VCA and BV on Hep G2 cells were determined by 3- (4, 5-dimethylthiazol-2-yl) -2, 5-diphenyltetrazolium bromide (MTT) assay in vitro. VCA and BV killed Hep G2 cells in a time- and dose-dependent manner.

Results: The apoptotic cell death was then confirmed by propidium iodide staining and DNA fragmentation analysis. The mechanisms of action was examined by the expression of anti-apoptotic proteins and activation of mitogen-activated protein kinases. Treatment of Hep G2 cells with VCA activated poly (ADP-ribose) polymerase-1 (PARP-1) known as a marker of apoptosis, and mitogen-activated protein kinases signaling pathways including SAPK/JNK, MAPK and p38. BV also activated PARP-1, MAPK, p38 but not JNK. The expression level of anti-apoptotic molecule, Bcl-X, was decreased by VCA treatment but not BV. Finally, the phosphorylation level of ERM proteins involved in the cytoskeleton homeostasis was decreased by both stimuli.

Conclusion: We examined the involvement of kinase in VCA or BV - induced apoptosis by using kinase inhibitors. VCA-induced apoptosis was partially inhibited by in the presence

Key Words : Mistletoe, Bee venom, Apoptosis, Liver cancer

\section{Introduction}

The rate of liver cancer in Korea is estimated at 30.5 per 100,000 men and 7.6 per 100,000 women, and the third annual report on the Korea Central Cancer Registration Project showed that it was the seventh for men and the seventh for women, which was higher than for other OECD countries ${ }^{1), 2}$.

The mistletoe is a plant parasitic on shrubs that has long been used as a medicinal plant, and attempts to use it in malignant tumors have recently been made using the extract ${ }^{3)}$.

Mistleto extracts are known to cause changes in the human immune system, and because of these immune-control effects, malignant tumors such as malignant lymphoma, multiple myeloma, leukemia are treated, malignant tumors are intended to prevent recurrence after primary treatment, or pre-cervative

\footnotetext{
- Received : 20 December 2018

- Revised : 26 December 2018

- Accepted : 26 December 2018

- Correspondence to: Seong-Woo Lim

Dept of Korean Internal Medicine, Ilsan Oriental Hospital of Dongguk University

Sik sa-dong Dog-gu II san Go-yang, Republic of Korea

Tel: +82-31-961-9043, E-mail: omdlsw@naver.com
} 
tumors such as chronic hepatitis B, and primary bone treatment of patients ${ }^{4}$.

The anti-cancer effects on Be Venom were actively implemented both at home and abroad, and the effects of cancer were reported due to the ingredients of Bong-dock, immunotherapy, pain, and so on. Be Venom is peptide components (melithin, adolapin, MCD sensitive, etc.), enzymes (PLA2, Hyaluronidase, Glucosidase, etc.), amines (histamin, epinephrine, etc.), non-ptitious components Beef poison is 1.3 percent, ph 5.2 percent bitter, weak-tasting, and 75 percent protein $^{5)}$.

In this study, we report that mistletoe and Be Venom were carefully studied to induce apoptosis of Hep G2, the liver cancer cell owner.

\section{Material and Methods}

\section{Preparations of bee venom}

$1 \mathrm{~g}$ of the poison Apis Melipera ligustica (West honey bee, Sigma, USA) was dissolved in the poison distilled water.

The mistletoe was purchased from Viscum album colorectum agglutin, VCA (Related per Cheongun, South Gyeongsang and South Korea) and used as the extraction method below.

\section{2) Preparation of a mistleto extract solution}

After grinding the leaves and stems of mistletoe into water at room temperature for 48 hours, the supernatant obtained by filtering them to freeze and dry them. After 96 hours, $2.5 \mathrm{~g}$ was filtered and stored at minus $80^{\circ} \mathrm{C}$.

\section{Method}

\section{1) Cellular stock and cell culture}

The hepatoma cell line and the Hep G2 cell used in the experiment were purchased from the American
Type Culture Collection (Rockville, MD). Cells were incubated using Dulbecco's modified Eagle's Medium (DMEM, Invitrogen, USA) containing 10\% Fetal Bovine Serum (FBS; Invitrogen, USA) at $37^{\circ} \mathrm{C}$ and 5\% CO2 incubator. To prevent contamination, $100 \mathrm{ut} / \mathrm{ml}$ phenicillin, 100ug/ml streptomin (Gibco/BRL, USA) was added as an antibiotic. Trypsin-EDTA (Gibco/BRL, USA) was treated and stratified. The badge was exchanged every two or three days.

\section{2) Cellular activity measurement (MTT allay)}

MTT ((4,5-dimethylthiazol-2-yl)-2,5-diphenyltrazolium bromide, Sigma) alay was conducted using Sladowski's method. MTT assay is a test method that utilizes the ability of cells to reduce MTT titrazol, a yellow soluble substrate, to a green-colored MTT FORMazan by dehydrogen enzyme. The absorption of MTT formazan is greatest at a wavelength of $580 \mathrm{~nm}$, where the absorbance measured is reflected in the oxidative power of a cell that is alive and has a strong metabolismo).

MTT assembly was first incubated for 24 hours after 16 hours of Hep G2 cells (5x103 cells/well) in a 12 cell plate. And 3-(4-Dimethylthiazol-2-yl)-2,5-diphenyltetra-zolium bromide (MTT). Sigma) $2 \mathrm{mg} / \mathrm{ml}$ was added, incubated in the incubator for 4 hours, then dissolved with dimethyllsulfoxide (DMSO; Sigma) and measured absorbency with a microplate reader (Molecular devices, USA) at a wavelength of $580 \mathrm{~nm}$ to calculate cell survival.

Cell viability (\%) is defined as: If the value of the normal range is controlled and the O.D. value is defined as 100 percent survival of the cell, and the value of the O.D. measured by the rest of the group is calculated as follows.

Cell Viability $=($ experiment $/$ control group $)$

3) Medication of inhibitors

PH3K inhibitor (LY2942), p38 MAPK inhibitor 
(SB203580), MAPK inhibitor (PD98059), and JNK inhibitor (SP600125) (Calbiochem, USA) treated the extraction and sterilization rates before the end of 30 minutes and then treated them with the MTT method.

\section{4) Western blot analysis method}

All cell solvents were made by boiling cells within a sample buffer $(66.5 \mathrm{mmol} / 1 \mathrm{Tris}-\mathrm{HCl}, \mathrm{pH} 6.8,2 \%$ SDS, 20\% glycerol, 10\% 2-mercaptoethanol). Protein doses were used in the bicinchonic acid (BCA, Pierce) method. 50 ug of the quantified protein sample was separated by $4-12 \%$ sodium diecylsulfate-polyacrylamide gradient gel (Invitrogen) and transferred to the nitrocellulose paper (Amersham). It was confirmed that the protein was completely transferred by dyeing the membrane of protein with Ponceau-S. After washing it with a Tris-buffered saline (TBS-T) containing $0.1 \%$ Tween 20 , the protein was blocked with $5 \%$ de-fat milk solution for more than 30 minutes. p38 (p-p38), p38, MAPK (p-MAPK), MAPK, ERM (p-EMM), moesin, JNK (p-JNK), JNK antibodies, PARP-1, Bcl-x, and activated (Cell signing) are in the USAch After the second antibody reaction, the curtain was washed and the protein that they wanted was visualized through the advanced chemical protection system (ECL, Pierce). Visualization and quantitative analysis of proteins was done using image equipment (LAS-3000, Fujitsu

\section{5) DNA fragmentation}

$10 \mathrm{ug} / \mathrm{ml}$ of BV and $50 \mathrm{ug} / \mathrm{ml}$ of VCA beef were processed in Hep G2 cells ( $5 \times 105$ cells), then cells were recovered for 16 hours and 24 hours respectively, centrifugation was performed for 5 minutes at $800 \mathrm{rpm}$, $10 \mathrm{mM}$ Tris (pH7.4), $10 \mathrm{~m}$ EDTA ( $\mathrm{pH} \mathrm{8.0),} \mathrm{and} \mathrm{the}$ floating solution was filled with a buffer of $10 \mathrm{mM}$ (X00-1). Add $20 \mathrm{mg} / \mathrm{l}$ of RNase A and $20 \mathrm{mg} / \mathrm{l}$ of Proteinase $\mathrm{K}$ to react for another hour at $37{ }^{\circ} \mathrm{C}$ and centrifugation to obtain genomic DNA. Add TE buffer (10mM Tris (pH7.4) and 10mM EDTA (pH 8.0) to dissolve DNA and electro-activate the $1 \%$ agarose gel to check the band.

\section{6) FACS Analysis}

After processing $10 \mathrm{ug} / \mathrm{ml}$ of BV and $50 \mathrm{ug} / \mathrm{ml}$ of VCA milk fat in the Hep G2 cell (2x106 cells), recover the cells each 24 hours, wash them with cold PBS, and secure them at room temperature for 30 minutes. Then, add $0.05 \mathrm{mg} / \mathrm{ml}$ of RNase A to remove RNA and react for one hour at $37^{\circ} \mathrm{C}$. Then, add $50 \mathrm{~g} / \mathrm{ml}$ of Propium iodide (PI) to the specimen and react in the dark for 30 minutes. DNA analysis used ELITE ESP flow rateometer (Bekman-Coulter Inc., USA).

\section{7) Data analysis and statistical processing}

All measurements were expressed as the mean value standard deviation (mean \pm S.D.) and statistical analysis among each group of experiments performed one-way ANOVA of the SPSS program for windows, and post-verification was verified by Tukey test. The statistical significance of the whole experiment was recognized as significant if the $\mathrm{p}$ value was less than 0.05 .

\section{Result}

\section{Effect of Mistleto (VCA) on the survival rate of liver cancer cells}

The cell survival rate was observed 24 hours and 48 hours after mistletoe was treated by concentration to investigate the effect of mistletoe on the survival rate of liver cancer cells. Concentration-dependent degradation from $10 \mathrm{ug} / \mathrm{ml}$ to $200 \mathrm{ug} / \mathrm{ml}$ resulted in increased apoptosis after 48 hours (Figure 1). 


\section{The Effect of Bovine (BV) on the Survival} Rate of Liver Cancer Cells

Mistletoe used the previously well-known anti-cancer drug to compare and study the anti-cancer effect in liver cancer cells. The MTT method observed the effect on the survival rate of cells 24 hours and
48 hours after the poison was treated with liver cancer cells by concentration. Bong-dock significantly killed cells from a concentration of $5 \mathrm{ug} / \mathrm{ml}$ and at a concentration of $7.5 \mathrm{u} / \mathrm{ml}$, more than $50 \%$ of the cells were killed (Figure 2).

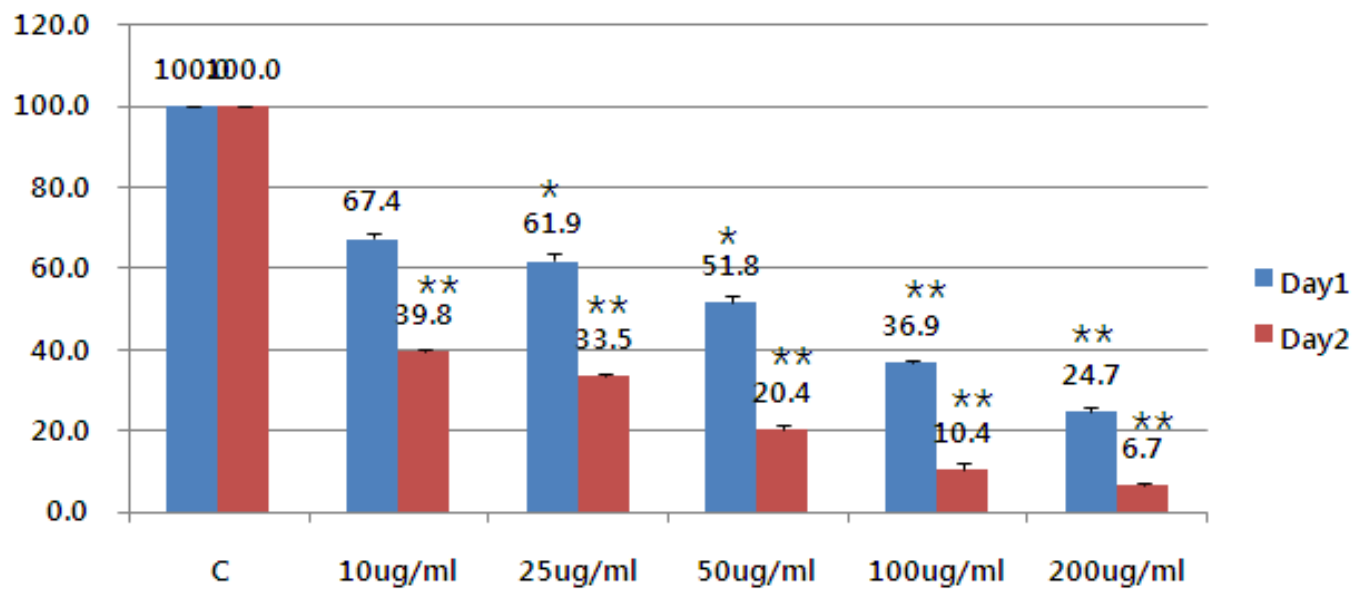

Fig. 1. Dose dependent cytotoxicity effect of VCA in Hep G2 cells. Hep G2 cells were exposed to different concentration of $10-200 \mathrm{ug} / \mathrm{ml}$ of VCA. Cell viability was measured by MTT assay at $24 \mathrm{~h}$ and $48 \mathrm{~h}$ after VCA addition. Data, expressed as percentage of control (Con), are the mean \pm SEM of three separate experiments. ${ }^{*} p<0.05$ vs control, ${ }^{* *} p<0.01$ vs control

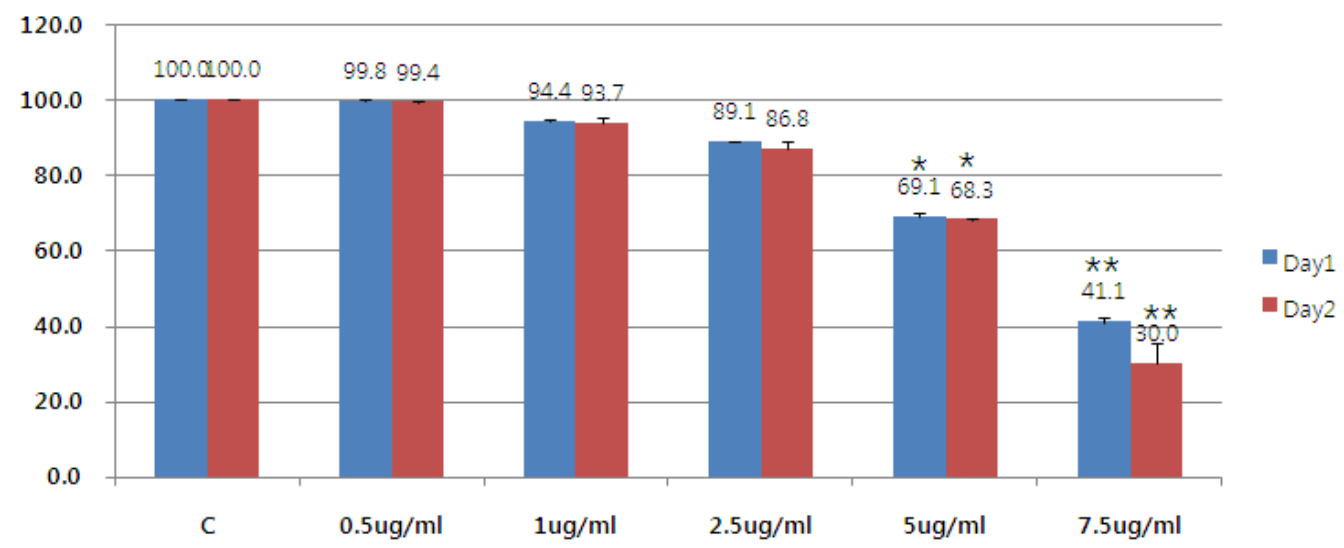

Fig. 2. Dose dependent cytotoxicity effect of BV in Hep G2 cells. Hep G2 cells were exposed to different concentration of $0.5-7.5 \mathrm{ug} / \mathrm{ml}$ of BV. Cell viability was measured by MTT assay at $24 \mathrm{~h}$ and $48 \mathrm{~h}$ after BV addition. Data, expressed as percentage of control (Con), are the mean \pm SEM of three separate experiments. ${ }^{*} p\langle 0.05$ vs control, ${ }^{*} p<0.01$ vs control 


\section{Mystery mistletoe and Bongtoe are the} two most successful liver cancer cells in Korea.

\section{1) DNA fragmentation}

The electroactivity was used to observe if chromosome DNA in the nucleus was cut to see if the apoptosis of the liver cancer cells in mistletoe and Bongto was achieved. We were able to see chromeoseome DNA cut into a ladder in 16 hours and 24 hours by Bong-dok and Mistleto (Figure 3).

\section{2) PARP-1 expression}

Electrostatic activity was used to observe that the nucleus was cut off when mistletoe and poison induces apoptosis, and it was confirmed that the PARP-1 was activated. PARP-1 increased at activation by a small band of $29 \mathrm{kDa}$ and observed that the cut band of

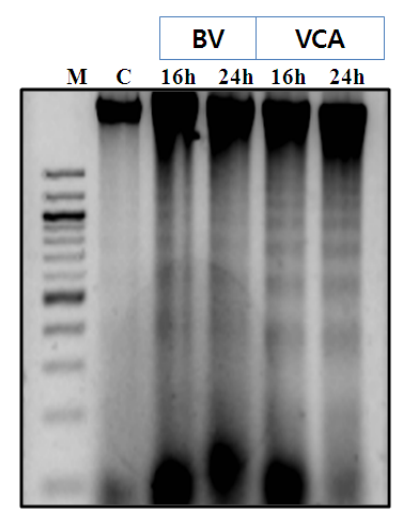

BV : $10 \mathrm{ug} / \mathrm{ml}$

VCA : $50 \mathrm{ug} / \mathrm{ml}$

\section{M: marker}

C: control

Fig. 3. Electrophoretic analysis of genomic DNA of Hep G2 cells treated with VCA $(50 \mathrm{ug} / \mathrm{ml})$ and BV (10 $\mathrm{ug} / \mathrm{ml})$. Cells were incubated for 16 and $24 \mathrm{~h}$ with or without VCA and BV. The genomic DNA was analysed by electrophoresis on a $1 \%$ agarose gel containing SYBR green.

PARP-1 by mistletoe and mutilation increased over time (Figure 4).

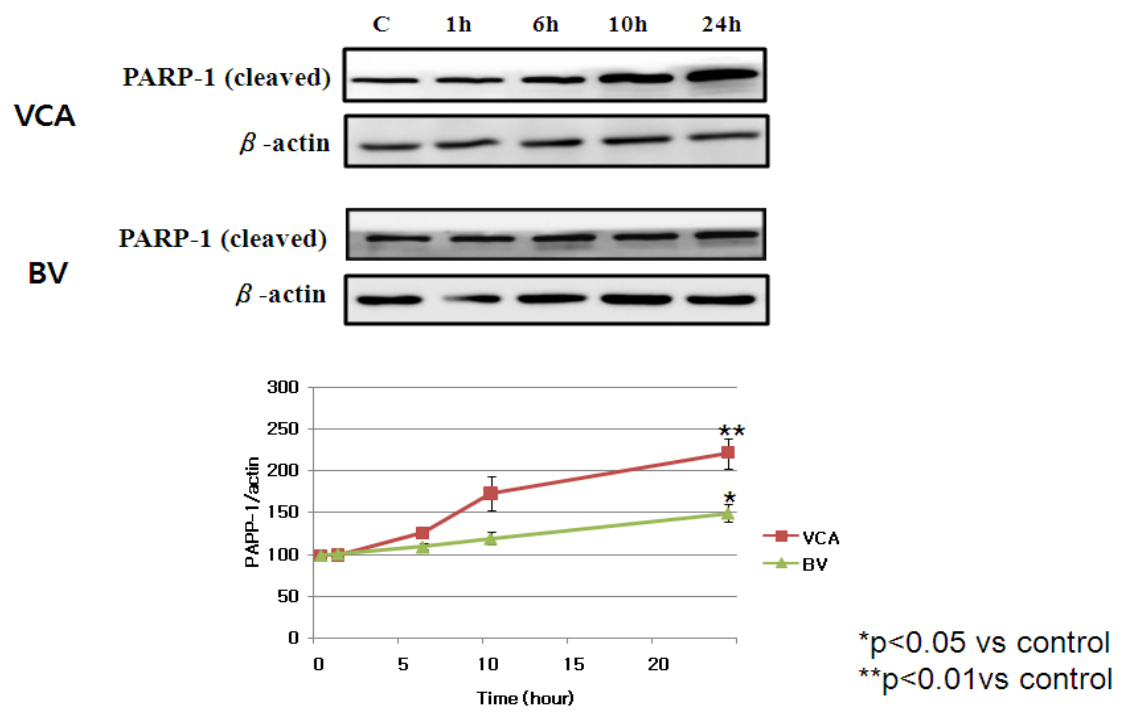

Fig. 4. Effect of VCA and BV on the expression of cleaved PARP-1 in Hep G2 cells. Hep G2 cells treated with VCA $(50 \mathrm{ug} / \mathrm{ml})$ and BV $(10 \mathrm{ug} / \mathrm{ml})$ for the indicated time. After that, whole cell lysates were electrophoresed in SDS-PAGE and analyzed by immunoblotting with anti-cleaved PARP-1 or actin antibody. The intensity of cleaved PARP-1 and and actin bands were quantitated by densitometric analysis, and the amounts of cleaved PARP-1 were normalized versus actin. The data represent the means \pm S.E. of three independent experiments. C: Unstimulated cells. 


\section{3) $\mathrm{Bcl}-\mathrm{x}$ expression}

Observing the accents of Bcl-x on a time-by-hour basis after mistreatment, mistletoe showed that only Mistletoe significantly decreased the amount of Bcl-x from six hours to 24 hours. These results suggest a different system of cell death signal transmission between Bong-dok and Mislotto (Figure 5).

\section{4) FACS analysis}

After the treatment, cells were fixed at 9 hours and the nucleus was dyed to observe the distribution by cell cycle using flow chromometer. The number of cells in the G0/G1 phase has increased statistically significantly and the number of newly synthesized Sphases has also decreased by treatment of mistletoe and poison. These results suggest that mistletoe and bovine may also be partially involved in arresting the cell cycle of G0/G1 (Figure 6).
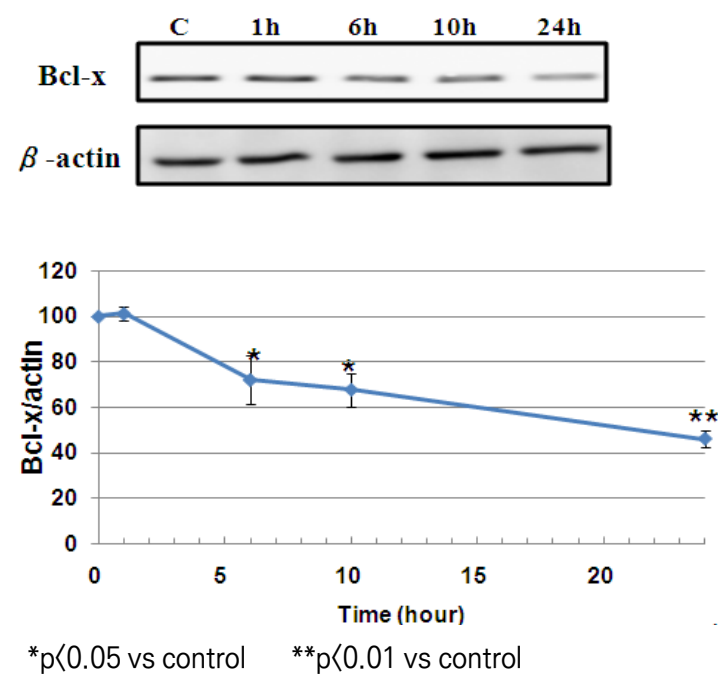

Fig. 5. Effect of VCA on the expression of $\mathrm{Bcl}-x$ in Hep G2 cells. Hep G2 cells treated with VCA (50 ug/ml) for the indicated time. After that, whole cell lysates were electrophoresed in SDS-PAGE and analyzed by immunoblotting with anti-Bcl-x or actin antibody. The intensity of Bcl-xand and actin bands were quantitated by densitometric analysis, and the amounts of $\mathrm{Bcl}-\mathrm{x}$ were normalized versus actin. The data represent the means \pm S.E. of three independent experiments. C: Unstimulated cells.
Control

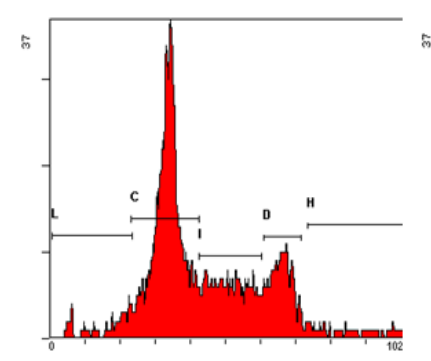

Fเs Lin

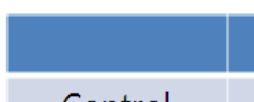

Control

VCA

BV
VCA

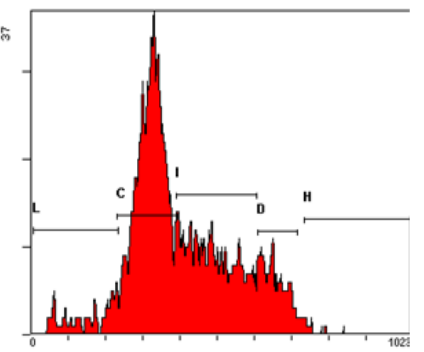

FL3 Lin
BV

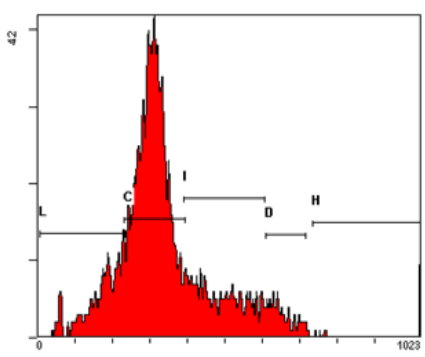

FLs Lin

\section{G0/G1}

G2/M

$\mathrm{S}$

$36.7 \pm 3.1$

$21.4 \pm 4.2$

$13.8 \pm 2.6$

$62.3 \pm 2.3^{*}$

$19.1 \pm 2.4$

$7.2 \pm 1.1^{*}$

\section{$52.1 \pm 4.8^{*}$}

$28.6 \pm 1.6$

$10.5 \pm 2.9^{*}$

Fig. 6. Effect of VCA and BV on the cell cycle of Hep G2 cells. Hep G2 cells treated with VCA (50 ug/ml) and BV $(10 \mathrm{ug} / \mathrm{ml})$ for $9 \mathrm{~h}$ and then fixed and stained with PI. ${ }^{*} \mathrm{p}<0.05$ vs control. 


\section{5) Activating MAPK family}

The activity of MAPK/ERK, p38 MAPK, and JNK of the proteins reported to increase in activity in the event of mistletoe and bovine killing the liver cancer cells was observed using phosphorylation-specific antibodies ${ }^{6,7), 8}$. Mistletoe continued for 24 hours from 6 hours after drug treatment, as phosphorylation of
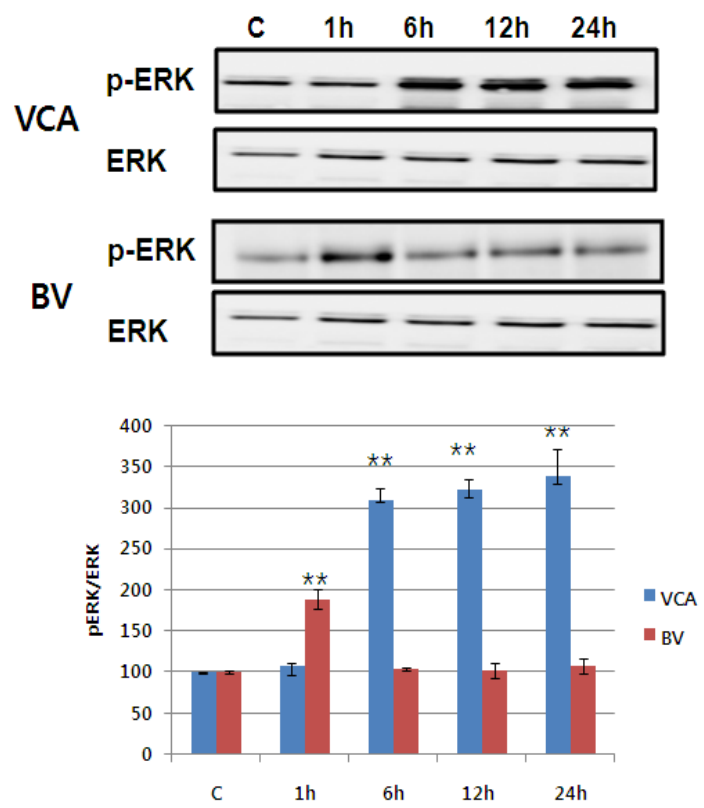

${ }^{*} p<0.01$ vs control.

Fig. 7. VCA and BV induces ERK phosphorylation in Hep G2 cells. Hep G2 cells were seeded in 6 well plates and were stimulated with $50 \mathrm{ug} / \mathrm{ml}$ of VCA and $10 \mathrm{ug} / \mathrm{ml}$ of BV for $1,6,12$, or $24 \mathrm{~h}$. After that, whole cell lysates were electrophoresed in SDS-PAGE and analyzed by immunoblotting with anti-p-ERK or ERK antibody. The intensity of phosphorylation and total ERK bands were quantitated by densitometric analysis, and the amounts of phosphorylated ERK were normalized versus total ERK. The data represent the means \pm S.E. of three independent experiments. C: Unstimulated cells.
MAPK/ERK, p38 MAPK, and JNK began to increase three times more than that of controls. On the other hand, Bong-dok returned to the control level in six hours after the drug was processed, with the phosphorylation of MAPK/ERK and p38 MAPK doubling in just one hour. No activity of JNK was observed (Figure 7-9).
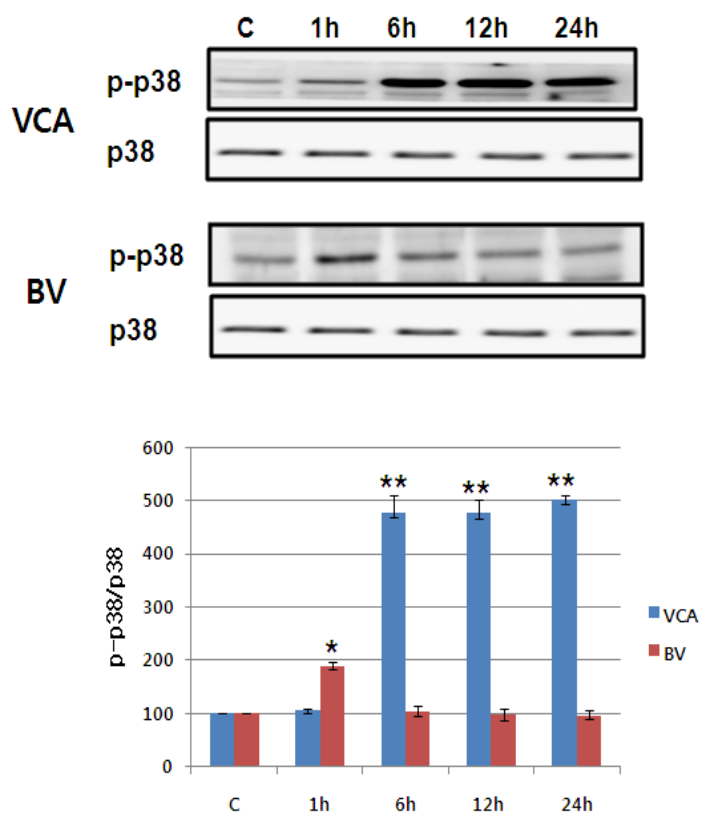

${ }^{*} p<0.05$ vs control. ${ }^{* *} p<0.01$ vs control.

Fig. 8. VCA and BV induces p38 phosphorylation in Hep G2 cells. Hep G2 cells were seeded in 6 well plates and were stimulated with $50 \mathrm{ug} / \mathrm{ml}$ of VCA and $10 \mathrm{ug} / \mathrm{ml}$ of BV for $1,6,12$, or $24 \mathrm{~h}$. After that, whole cell lysates were electrophoresed in SDS-PAGE and analyzed by immunoblotting with anti-p-p38 or p38 antibody. The intensity of phosphorylation and total p38 bands were quantitated by densitometric analysis, and the amounts of phosphorylated p38 were normalized versus total $\mathrm{p} 38$. The data represent the means \pm S.E. of three independent experiments. C: Unstimulated cells. 

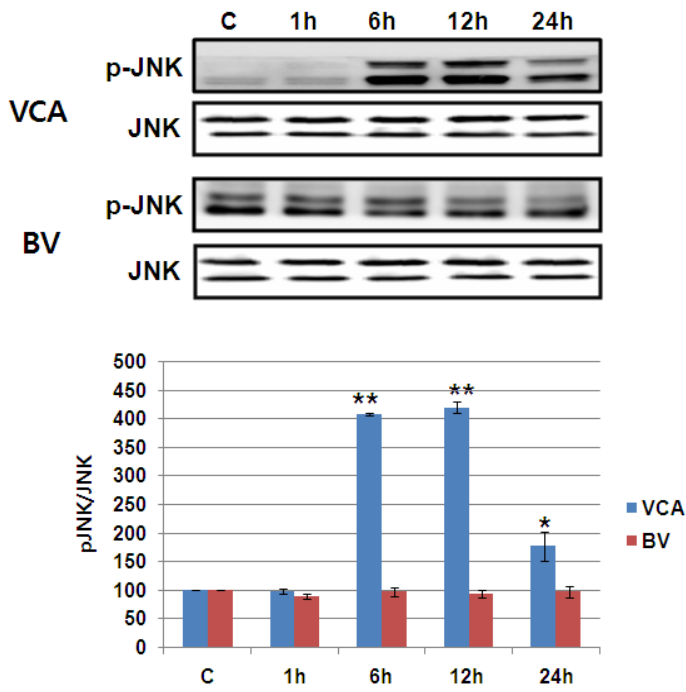

${ }^{*} p<0.05$ vs control. ${ }^{* *} p<0.01$ vs control.

Fig. 9. VCA induces JNK phosphorylation in Hep G2 cells. Hep $\mathrm{G} 2$ cells were seeded in 6 well plates and were stimulated with $50 \mathrm{ug} / \mathrm{ml}$ of VCA $10 \mathrm{ug} / \mathrm{ml}$ of BV for 1, 6, 12, or $24 \mathrm{~h}$. After that, whole cell lysates were electrophoresed in SDS-PAGE and analyzed by immunoblotting with anti-p-JNK or JNK antibody. The intensity of phosphorylation and total JNK bands were quantitated by densitometric analysis, and the amounts of phosphorylated JNK were normalized versus total JNK. The data represent the means \pm S.E. of three independent experiments. C: Unstimulated cells.

\section{6) Activating ERM proteins family}

The degree of activity of ERM protein, known to affect the cellular skeleton with another protein related to apoptosis, was performed as immunosuppression ${ }^{9)}$. As shown in Figure 10, phosphorylation of ERM protein was reduced by mistletoe not more than 24 hours later. However, the number of bong poisons continued to decrease up to 24 hours, beginning with a six-hour decline. However, the amount of ERM protein has not changed, suggesting that only the phosphorylation of ERM proteins has decreased (Figure 10).
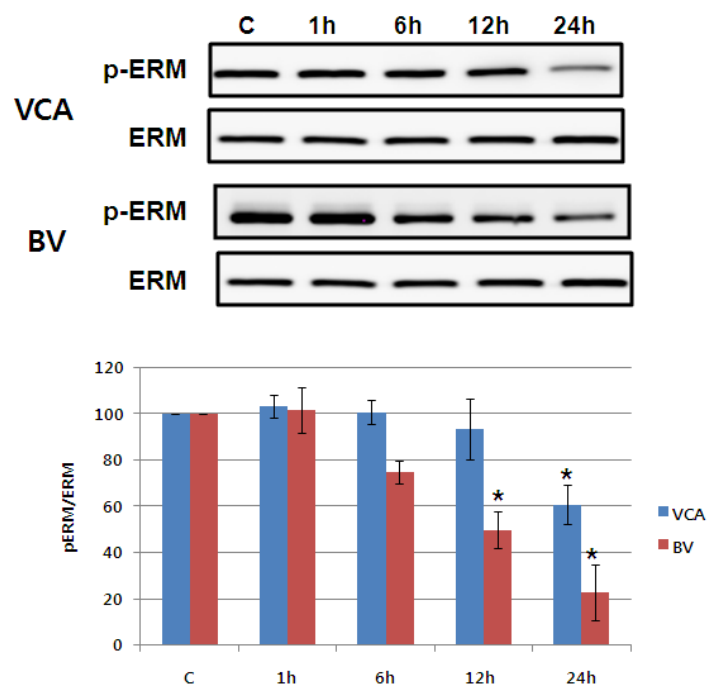

${ }^{*} \mathrm{p}<0.05$ vs control

Fig. 10. VCA and BV induces ERM proteins phosphorylation in Hep G2 cells. Hep G2 cells were seeded in 6 well plates and were stimulated with $50 \mathrm{ug} / \mathrm{ml}$ of VCA and $10 \mathrm{ug} / \mathrm{ml}$ of BV for 1, 6, 12, or $24 \mathrm{~h}$. After that, whole cell lysates were electrophoresed in SDS-PAGE and analyzed by immunoblotting with anti-p-ERM or ERM antibody. The intensity of phosphorylation and total ERM bands were quantitated by densitometric analysis, and the amounts of phosphorylated ERM were normalized versus total ERM. The data represent the means \pm S.E. of three independent experiments. C: Unstimulated cells.

7) Identification of the signal transmission system for apoptosis of cells

We used active inhibitors of JNK, p38, and MAPK among the proteins that are known to be stressed or activated in apoptosis to identify the signal path of apoptosis by mistletoe and poison ${ }^{6,7), 8), 9)}$. These inhibitors were given to the cells in advance, and mistletoe and poison were treated to perform MTT assay 24 hours after they were killed. As shown in Figure 11 , the apoptosis of cells by mistleto was partially inhibited by JNK and p38 inhibitors. The cell killing effect of the poison was partially inhibited by the treatment of p38 inhibitors (Figure 11, 12). 


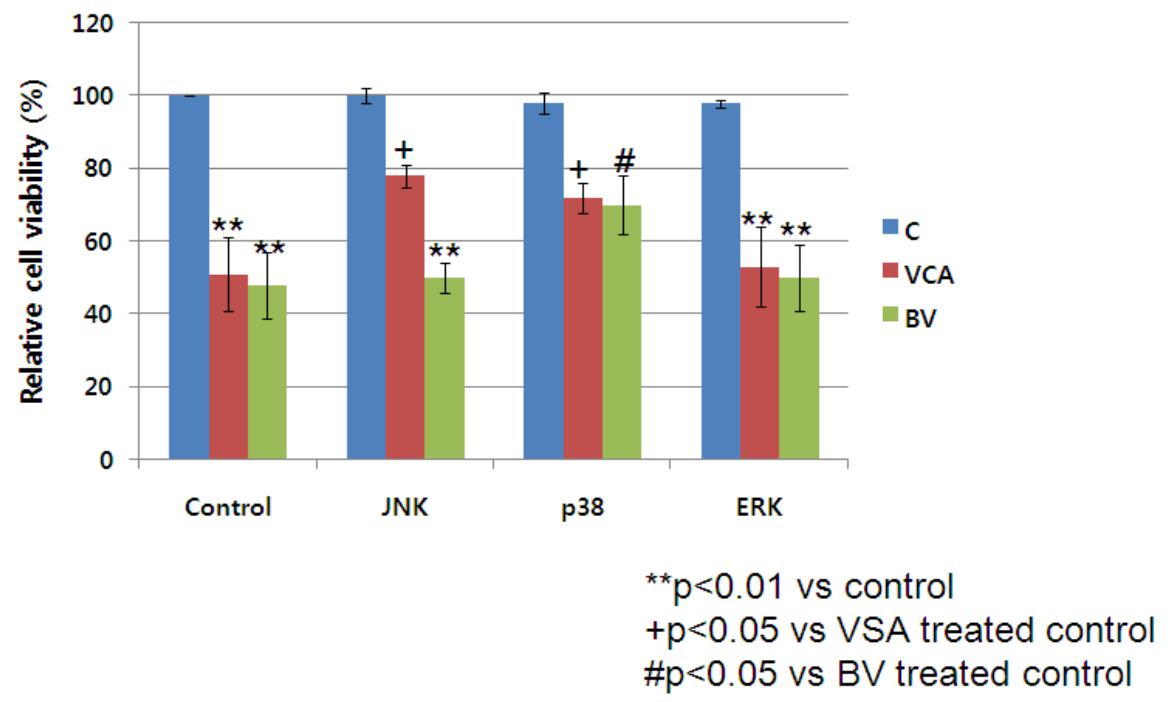

Fig. 11. MAPK family activation involved in the VCA and BV-induced cytotoxicity effect in Hep G2 cells. Hep G2 cells were pre-treated with 15 UM JNK, p38 or MAPK inhibitor, SP600125, SB203580 or PD98059, respectively for $30 \mathrm{~min}$ before the addition of $50 \mathrm{ug} / \mathrm{ml}$ of VCA and $10 \mathrm{ug} / \mathrm{ml}$ of BV. Cell viability was measured by MTT assay at $24 \mathrm{~h}$ after addition. Data, expressed as percentage of control (Con), are the mean \pm SEM of three separate experiments

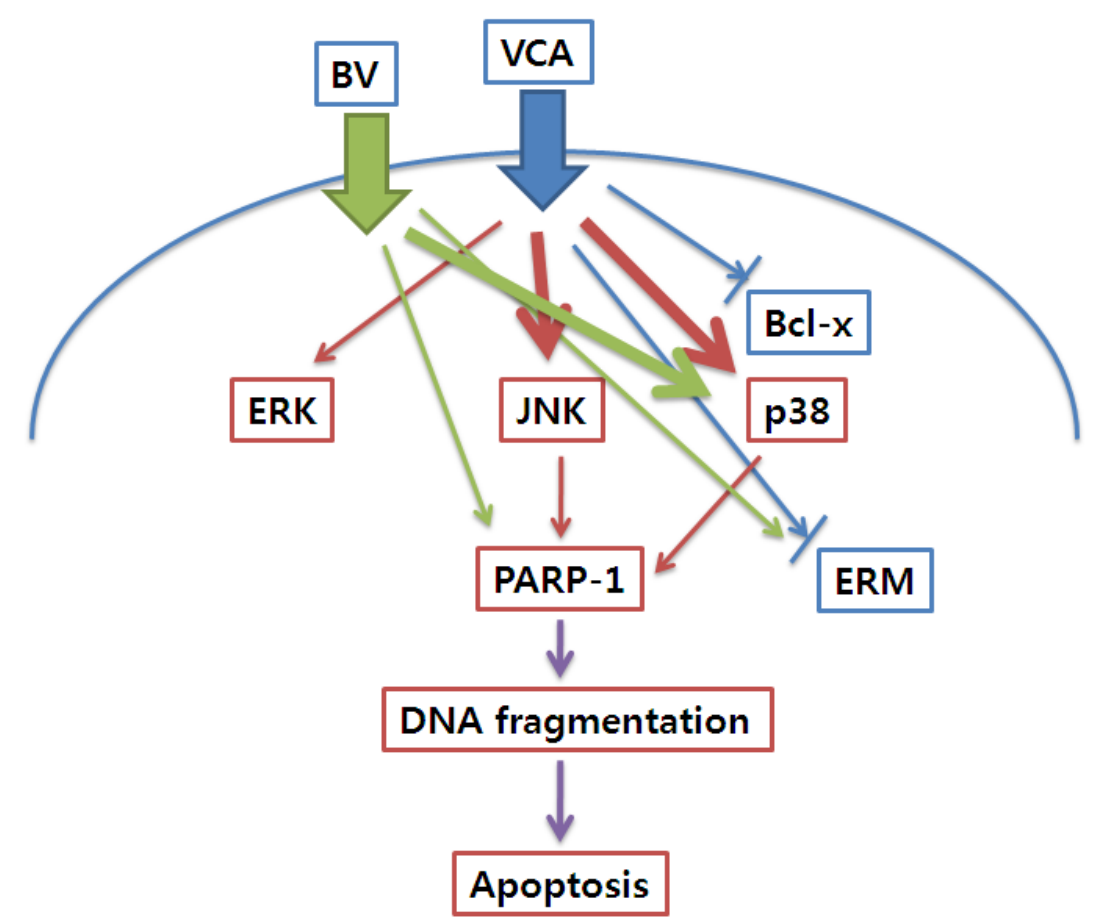

Fig. 12. Signaling pathway activated by VCA and BV treatment in Hep G2 cells. 


\section{Result \& Discussion}

In Korean medicine, mistletoe is known to be effective in controlling the central, diuretic, coercive, sedative, anti-cancer, and cardiovascular events.

The efficacy of mistletoe includes quercetin, quercitrin, aerialin, and oleanolic acid, among which quercetin induces immune suppression by reducing the number of white blood cells such as eosinophil and neutropyl, and oleanolic acid has been shown to be immune-boosting and anti-immune reactions.

There are reports that Mistletoe therapy uses different types of mistletoe to treat cancer ${ }^{10)}$, and that the lectin-II component induces apoptosis for the human myeloid leukemia cells ${ }^{11)}$. Immunodeficiency substances extracted from Visum album L. are applied to cancer and $\operatorname{AIDS}^{12)}$. Fischer et $\mathrm{al}^{13)}$ showed a sensitive response to the adjustment of $\mathrm{T}$ lymphocytes in $\mathrm{CD} 4+$ by processing mistletoe extract, while Park et $\mathrm{al}^{14)}$ reported that the lectine component of mistletoe had an active lymphocytes effect, and Tasneem et al. ${ }^{15)}$ reported that fermentation of mistletoe extract had an effect on inhibiting tumor cells.

Be Venom (BV) is a chemical that is highly likely to be characterized by both natural and hormonal agents and bio-therapeutics, and is a Pharmacology peptide components such as methylin, agolapin, MCDptide, etc., and enzymises (PLA2,alerton, GLA2, and GosThere is $\mathrm{A} 2$ et al. ${ }^{5), 16)}$.

MAPK (Mitogen-active proteinase), which is responsible for various functions such as cell proliferation, differentiation, and apoptosis, delivers extracellular stimuli to the nucleus from the membrane of cells to the receptor of growth hormones, cytokines, and stress de.

MARK can be classified as ERK (cell's signal activation enzyme), JNK (c-JUN N-terminal active enzyme), p38 MAPK (ERK1/2) is primarily concerned with the signal transmission of growth hormones and is responsible for the growth and differentiation of cells, and the pKNAP, which are classified as stress-active enzymes, can be triggered by external pKNAPs.

In response, the author measured the degree of cell activity by concentration, time, and the activation of the protein involved in cell survival and apoptosis after administration of mistletoe extract and poison to Hep G2, a cell owner of liver cancer cells.

In general, in order to find efficacy for the development of new anti-cancer drugs or to find the sensitivity of the previously developed anti-cancer drug, it is necessary to examine the growth inhibition of tumor growth of the drugs outside of the living system prior to the application phase of animal testing. Several methods have been developed to measure the cell's survival indirectly, since the number of samples is not available because it requires too much effort and time, even though a direct and ideal way of accurately measuring cells or living cells is to be treated with a trypan blueter in cells, and then count living cells using a microscope and a hemocytmeter. To this end, the in Vitro pharmacological search method of cancer drugs is widely used as a cytotoxic and cytotoxic search method by using 96-well plates and using ELISA reader to read many specimens quickly and objectively. MTT testing is used extensively for the purpose of primary screening tests on the sensitivity of cancer drugs, but can also be very useful for testing the sensitivity of cells to growth factors. In this experiment, the survival rate of cells by MTT test was determined by the concentration of mistletoe and poison and liver cancer cells dying. However, when comparing the two substances' anticancer effects by dose, mistletoe twice as much as Bongto's in order to achieve the same cellular toxicity effect 24 hours after treatment, but 48 hours later there were no differences in the effect of apoptosis of the two substances. These results show that the drug 
lasts a long time, with mistletoe dying over time compared to the poison

In general, if a cell's death occurs due to toxicity, the cell's death is caused by necrosis, inflammation, and cell death through one of the pathways. A necrosis is a group cell death that occurs quickly, and the characteristic of a collective cell death is that the membrane of the cell is destroyed first. But cell death, also known as apoptosis, is caused by the condensation and decay of the nucleus through various pathways inside the cell, and among the various cell death observed from the toxin, cell death caused mostly by the apoptosis. The most deeply studied biochemical event in Apoptosis is the amputation of the nuclear DNA double helix. These fragments appear in the form of ladders of DNA characterized by the agar-sagel electrophoresis 16). The protein involved in the cutting of these nuclear DNA double helix is known to be PARP-1 ${ }^{17), 18)}$. PARP-1 is a zinc dependent protein that is known to be activated when DNA strand breaks are triggered ${ }^{19)}$, especially when cells $\mathrm{die}^{20)}$. In this study, we found that DNA was cut into a ladder by mistletoe and poison, and we could observe the activated PARP-1. Therefore, these results suggest that mistletoe and bovine were caused by apoptosis, not necrosis, when they induced apoptosis. Typically, cell death apoptosis is done through a series of intracellular signalling systems, among which reducing the amount of protein that inhibits apoptosis also contributes to the cell death. A typical protein that suppresses these cell apoptosis is $\mathrm{Bcl}$ family protein ${ }^{21)}$ Mistletoe began significantly reducing the expression of Bcl-x after six hours and then continued to decrease until 24 hours.

Observed by FACS as to which cell cycle was stopped by mistletoe and Bongto induces cell death, which led to cell proliferation and apoptosis, the number of cells in the $\mathrm{G} 0 / \mathrm{G} 1$ phase increased statistically significantly and the number of newly synthesized spase was also reduced. These results suggest that mistletoe and bong poisons may also be partially involved in arresting the cell cycle of $\mathrm{G} 0 / \mathrm{G} 1$. preparations for bee venom.

As this apoptosis progresses, a series of intracellular signalling systems are activated. MAPK family (MAPK/ERK, p38 MAPK, JNK) is known as their representative protein 6-8). JNK and $\mathrm{p} 38$ are known to be proteins activated by external stresses such as osmotic stress, UV irradiation, heat shock, oxidative stress, probabilistic cytokines ${ }^{22)}, \mathrm{p} 38$ and JNK are known to be suppressed by external stresses that inherently inhibit the activity. ${ }^{23), 24)}$. Conversely, the MAPK family protein is known to be involved in cell survival or differentiation, which is controlled by the degree of activation of the MAPK family protein in the cell or by the balance of the period ${ }^{22}$. Persistent activation leads to apoptosis of cells, but temporary activation leads to cell survival or differentiation. ${ }^{22)}$ This study shows that phosphorylation of MAPK family protein by mistleto has increased threefold in six hours after treatment to 24 hours. However, it only activated MAPK/ERK and p38 MAPK and doubled in just one hour after the poison was processed, recovering to the baseline in six hours. In addition, the apoptosis by mistletoe was partially recovered by treatment of JNK and p38 specific inhibitors, and the apoptosis by the poison was partially mitigated by p38 inhibitors. In the case of mistletoe, it is consistent with the existing results to demonstrate that the activity of JNK and p38 is sustained and strong enough to cause apoptosis of cells. However, unlike the existing results, the apoptosis of cells was partially inhibited by the treatment of p38 active inhibitors, despite the temporary activation of $\mathrm{p} 38$.

These results suggest that even a transient p38 activity can lead to partial apoptosis, suggesting the involvement of other intracellular signalling systems.

ERM proteins exist in inert state through in-molecular 
interaction within the cytoplasm, but when signals are transmitted from outside, the binding is released and activated to link cell membrane proteins with bone protein. Activation mechanisms are the phosphorylation of the Treonin remnants of the C-terminal. The upper control factor of ERM protein, identified so far, is Rho. The protein is known as an active-based cytoskeletal organization and is reported to have a direct impact on the activation of ERM proteins. Another upper element of ERM protein is known as $\mathrm{Akt}^{25}$. Akt protein is protein-serine/threonin case, $\mathrm{PKB}$, whose function is known to play an important role in the development and progression of various cancer cells. The inhibition of ERM proteins is the dehumanization of the trenaline residue that was phosphated. This dehumanization is known to occur in the in vitro by myosin light chain phosphatase and protein phosphatase $2 \mathrm{C}$, which occurs in the early stages of apoptosis with micro-fusion damage, which increases ERM protein's movement to the cell vagina ${ }^{9)}$. Akt's dehumanization is known due to mistletoe's anti-cancer mechanisms ${ }^{26}$. Therefore, Akt is likely to be involved in dehumanizing the ERM protein by mistleto.

\section{Acknowledgements}

In order to experimentally compare and study the anticancer mechanisms that mistletoe and bee venom affect liver cancer cell owner Hep G2, measure the activity of each cell using the MTT layeray method and the activation of the proteins involved in cell survival and apoptosis, and induce apoptosis, JK 38

\section{References}

1. Ahn YO, Park BJ, Yoo KY, Lee HS, Kim CY, Shigematsu T. Incidence estimation of primary liver cancer among Koreans. Journal of Korean
Cancer Association. 1989:241-248.

2. The Ministry of Health and Welfare. the Korea Central Cancer Registration Center, and the annual report of Korea's Central Cancer Registration Project. 2015

3. Stein GM, Schetzel M, Bussing A. Mistletoe in immunology and the clinic(short review). Anticancer Research. 1998;18:3247-9.

4. Stein GM, Pfuller U, Schietzel M. Viscotoxin-free aqueous exyracts from European mistletoe (Viscum album L.) stimulate activity of human granulocytes. Anticancer Research. 1999;19:2925-8.

5. Son DJ, Lee JW, Lee YH, Song HS, Lee CK, Hong JT. Therapeutic application of anti-arthritis, pain-releasing and anticancer effects of bee venom and its constituent compounds, Pharmacol Ther. 2007 Aug;115(2):246-70.

6. Xia, Z., Dickens, M., Raaingeaud, J., Davis, R. J. and Rincon, M. E. : Opposing effects of ERK and JNK-p38 MAPkinases on apoptosis. Science 270, pp.1326-1331, 1995.

7. Karasavvas, N. and Zakeri, Z. Relationships of apoptotic signaling mediated by ceramide and TNF-alpha in U937 cells. Cell Death Differ. 1999;6:115-123.

8. Kawasaki H, Morooka T, Shimohama S, Kimura J, Hirano T, Gotoh Y. Activation and involvement of p38 mitogen-activated protein kinase in glutamate-induced apoptosis in rat cerebellar granule cells. J. Biol. Chem. 1997;272:18518-18521.

9. Kondo T, Takeuchi K, Doi Y, Yonemura S, Nagata S, Tsukita S. ERM (ezrin/radixin/moesin)-based molecular mechanism of microvillar breakdown at an early stage of apoptosis. J Cell Biol. 1997;139(3):749-58.

10. Bussing A. Suzart K, Bergmann L, Pfuller U, Schietzel M, Schweizer K. Induction of apoptosis in human lymphocytes treated with Viscum album 
$\mathrm{L}$ is mediated by the mistletoe lectins. Cancer Lett. 1996;99:59-72.

11. Park RK, Kim MS, So HS, Jung BH, Moon SR, Chung SY, et al. Activation of c-Jun N-termonal Kinase 1(JNK1) in Mistletoe Lectin $\Pi$-induced Apoptosis of Human Myeloleukemic U937 Cells. Biochemical Pharmacology. 2000;60:1685-1691.

12. Stoss M, Peter E, Gorter RW. Decrease of activated lymphocytes four and nine hours after a subcutaneous injection of a Viscum album L. extract in healthy volunteers. Nat Immun. 1998;16(5-6):185-97.

13. Fischer S, Scheffler A. Kabelitz. Oligoclonal in vitro Response of CD4 $\mathrm{T}$ cells to vesicles of mistletoe extracts in mistletoe-treated cancer patients. Biomed Pharmacother. 2000;54(6):305-10.

14. Park WB, Kim HS, Na HB, Ham SS. Changes in the lethin content, $\mathrm{pH}$, temperature effects, and sugar-specific lymphocytic stimulation effects during mistletoe fermentation. Journal of Pharmaceutical Affairs. 1995;39(1:24-30)

15. Tasneem A, Khwaja O, Cecilia B, Stephanie P. Recent studies on the Anticancer Activities of Mistletoe(Viscum album) and Its alkaloids. Oncology. 1986;43(1):42-50.

16. Moon DO, Park SY, Choi YH, Kim ND, Lee C, Kim GY. Melittin induces Bcl-2 and caspase-3-dependent apoptosis through downregulation of Akt phosphorylation in human leukemic U937 cells, Toxicon. 2007 Sep 2;Epub ahead of print.

17. Hengartner MO. The biochemistry of apoptosis. Nature. 2000;407:770-6.

18. Chiarugi A. (2002) Poly(ADP-ribose) polymerase: killer or conspirator? The "suicide hypothesis" revisited. Trends Pharmacol. Sci. 23:122-129.

19. Lazebnik YA, Kaufmann SH, Desnoyers S, Poirier GG, Earnshaw WC. Cleavage of poly(ADP-ribose) polymerase by a proteinase with properties like
ICE. Nature. 1994 Sep 22;371(6495):346-7.

20. Chiarugi A. (2002) Poly(ADP-ribose) polymerase: killer or conspirator? The "suicide hypothesis" revisited. Trends Pharmacol. Sci. 23:122-129

21. Boise LH, González-García M, Postema CE, Ding L, Lindsten T, Turka LA, et al. bcl-x, a bcl-2-related gene that functions as a dominant regulator of apoptotic cell death. Cell. 1993 Aug 27;74(4):597-608.

22. Matsuzawa A, Ichijo H. Redox control of cell fate by MAP kinase: physiological roles of ASK1-MAP kinase pathway in stress signaling. Biochim Biophys Acta. 2008 Nov;1780(11):1325-36. Epub 2008 Jan 16. Review

23. Tibbles LA, Woodgett JR. The stress-activated protein kinase pathways, Cell. Mol. Life Sci. 1999;55:1230-1254.

24. Borsello T, Clarke PG, Hirt A, Vercelli M, Repici $\mathrm{DF}$, Schorderet J, et al. A peptide inhibitor of c-Jun N-terminal kinase protects against excitotoxicity and cerebral ischemia, Nat. Med. 2003;9:11801186.

25. Shiue H, Musch MW, Wang Y, Chang EB, Turner JR. Akt2 phosphorylates ezrin to trigger NHE3 translocation and activation. J Biol Chem. 2005;280(2):1688-1695.

26. Choi SH, Lyu SY, Park WB. Mistletoe lectin induces apoptosis and telomerase inhibition in human A253 cancer cells through dephosphorylation of Akt. Arch Pharm Res. 2004 Jan;27(1):68-76. 